\title{
Ueber das Capryliak.
}

Cahours hat mittelst des aus dem Ricinusöle dargestellten Caprylalkohols den jodwasserstoffsauren Aether dargestellt, denselben mit Ammoniak in alkoholischer Lösung zusammen eingeschmolzen und erhitzt. Er erhielt so in Wasser leicht lösliche grosse Krystalle von jodwasserstoffsaurem Capryliak, die bei der Behandlung mit Kali das :

Capryliak $\mathrm{C}^{16} \mathrm{H}^{19} \mathrm{~N}(=4 \mathrm{Vol}$. Dampf) gaben. Klares, farbloses Oel, vom Geruche des Ammoniaks, der zugleich an den Geruch erinnert, den dio Pilze haben. Leichter als Wasser, siedet bei $172^{\circ}$ bis $175^{\circ}$.

Der Salmiak ist stets zerfliesslich, krystallisirt in breiten, perlglänzenden Schuppen. Der Platinsalmiak derselben Base ist in Wasser löslich, krystallisirt in glänzenden, goldgelben Schuppen. Die Salze des Capryliaks mit Schwefelsäure und Salpetersäure sind krystallisirbar, mit Benzoylchlorid und Cumylamid giebt das Capryliak, die, dem Benzamid und Cumylamid entsprechenden Verbindungen. Behandelt inan es mit Jodüthyl, so entstehen, wie bei den homologen Basen, die Imid - und Nitrilbasen. (Compt. rend. T.39. - Chem.-pharm. Centrbl. 1854. No. 42.)

$B$.

\section{Gerbsaures Chinin.}

De Couseran giebt folgende Vorschrift zur Bereitung desselben.

Nimm schwefelsaures Chinin 5 Grm.

Destillirtes Wasser 100

Schwefelsture so viel als nöthig ist. Anderen Theils löse $10 \mathrm{Grm}$. Tannin in $190 \mathrm{Grm}$. kaltem destillirten Wasser. Letztere Lösung wird filtirt und nach und nooh in die Lösung des schwefelsauren Ohinins gegossen, lange ein Niederschlag entsteht, unter Zusatz von einigen Tropfen Ammoniak. Der Niederschlag wird gewaschen und bei gelinder Wärme getrocknet. (Jourm. de med. et de chir. prat. - Journ. de Pharm. d'Anvers. Mai 1854.)

A. 0 .

\section{Intersuchungen über das Birkenharz.}

Die Betula alba L. ist mehrfach Gegenstand chemischer Untersuchungen gewesen: Loritz entdeckte in der 